\title{
NACIONALISMO Y PATRIOTISMO \\ EN LA OBRA DE ANTONIO MACHADO
}

\author{
Nationalism and patriotism \\ in the work of Antonio Machado
}

\author{
ANDRÉS DE BLAS GUERRERO \\ Universidad Nacional de Educación a Distancia \\ ablas@poli.uned.es
}

Cómo citar/Citation

Blas Guerrero, A. de (2017).

Nacionalismo y patriotismo en la obra de Antonio Machado.

Historia y Política, 38, 289-314

doi: https://doi.org/10.18042/hp.38.10

(Recepción: 02/11/2015. Evaluación: 08/03/2016. Aceptación: 21/05/2017. Publicación: 10/11/2017)

\section{Resumen}

La evidente significación política de la obra de Antonio Machado no ha recibido una gran atención. Entre la numerosa bibliografía machadiana, las consideraciones de carácter político en absoluto son comparables a las de carácter estrictamente literario, filosófico o hasta religioso. Y esta observación es aplicable al tema del patriotismo y el nacionalismo. La notable influencia política que alcanzó Antonio Machado a lo largo de la II República y, especialmente, la Guerra Civil, y su significado como símbolo antifranquista a la lo largo de la dictadura, no oculta el dato de que su formación política y la consistencia de su consiguiente cosmovisión política no se caracterizan por su solidez.

\section{Palabras clave}

Guerra Civil; Segunda República; franquismo; Antonio Machado; nacionalismo. 


\section{Abstract}

The unquestionable political signification of Antonio Machado's literary work has not been accompanied by parallel scholarly attention to this dimension of his writing. The copious bibliography on Machado has not abounded in reflections on the political aspects of his work comparable to considerations of its literary, philosophical or even religious features. This observation is also applicable to the topic of patriotism and nationalism. The remarkable political influence that Antonio Machado exerted during the period of the Second Republic and, especially, the Spanish Civil War, and his significance as an anti-Francoist symbol throughout the Dictatorship must not conceal the fact that Machado's political preparation and the resultant consistency of his political worldview were not characterized by their soundness.

\section{Keywords}

Spanish Civil War; Second Spanish Republic; Francoism; Antonio Machado; nationalism. 
I. INTRODUCCIÓN. II. SORIA Y CASTILLA EN LA OBRA MACHADIANA. III. LA AMBIVALENCIA RESPECTO A UN SENTIMIENTO PATRIÓTICO. IV. EL GIRO EN LA GUERRA CIVIL. V. LOS NACIONALISMOS PERIFÉRICOS. VI. COMPONENTES CONTRADICTORIOS DE SU COSMOVISION POLÍTICA. VII. UNA OBSERVACIÓN SOBRE EL TEATRO MACHADIANO. VIII. CONCLUSIÓN. BIBLIOGRAFÍA.

\section{INTRODUCCIÓN}

Resulta evidente la significación política de la obra de Antonio Machado. Ya en los años de la II República, Machado es una personalidad respetada e influyente en la vida pública española. Por lo que hace a su actividad política, Paul Aubert ha hecho inventario de algunos datos significativos: el 21 de octubre de 1913 se adhiere a la Liga de Educación Política; el 9 de julio de 1915 firma el Manifiesto de adhesión a las naciones aliadas; el 18 de enero de 1917 el de la Liga Antigermanófila; el 26 de febrero de 1922 el Manifiesto por la libertad de cátedra; el 4 de marzo de 1922 el Manifiesto de la Liga Española para la Defensa de los Derechos del Hombre, y en 1926 el de Alianza Republicana ${ }^{1}$. Había sido un miembro activo de la Agrupación al Servicio de la República cuyo mitin de presentación en Segovia había presidido. En los años treinta fue miembro del Consejo Nacional de Cultura y del Patronato de Misiones Pedagógicas, e integrante del Comité Mundial para la Defensa de la Cultura. Su autoridad se agiganta en el desarrollo de la Guerra Civil. Los dirigentes republicanos del período 1936-1939 respondieron con diligencia a la rotunda actitud del poeta a favor de la legalidad. En noviembre de 1936, a instancias de Alberti y León Felipe, el poeta accede a ser evacuado junto a su familia del Madrid en guerra a Valencia. Allí es alojado primero en la Casa de Cultura y después en un chalé en Rocafort, en las cercanías de la nueva capital de la República. En Valencia se incorpora plenamente a los trabajos de propaganda y prensa del Gobierno republicano, colaborando en Cuadernos de la Casa de Cultura, Hora de España, el Servicio Español de Información y en gran número de periódicos. En los años de la guerra fue presidente del Patronato de la Casa de Cultura, vicepresidente del Consejo Nacional de Teatro, presidente honorario de la

$1 \quad$ Aubert (1994). 
Alianza de Intelectuales Antifascistas y presidente de honor del Congreso Internacional de Escritores para la Defensa de la Cultura. En los últimos momentos de vida de la República será trasladado a Barcelona, una vez más con su familia, alojado en el Hotel Majestic, primero, y en Torre Castañar, un chalé aristocrático en el Paseo de San Gervasio, después. Allí continúa su labor en defensa de la República. De Barcelona será evacuado a la frontera, hasta llegar a su destino final en Collioure.

Después de la guerra, Antonio Machado será objeto de recuperación por un sector de la Falange. Dionisio Ridruejo y los hombres del grupo Escorial llevarán a cabo esta tarea tras una previa despolitización de un Antonio Machado presentado como un manipulado por el bando republicano a lo largo de la Guerra Civil:

Don Antonio Machado, viejo, aunque fresco en sus facultades literarias, fue uno de estos secuestrados morales. Fue el propagandista "propagandeado». Su ingenuidad de viejo profesor desaliñado le hacía bueno para creer honradamente toda patraña y, sin más datos ni averiguación de ellos, consideró a los de enfrente tal como los próximos a él se los presentaban y a ellos mismos tal como en el plácido aislamiento quisieron presentárselo².

El propio Ridruejo rectificaría esta apreciación del poeta aceptando su condición de pensador y el calado de su filosofía en el conjunto de su obra ${ }^{3}$. Con todo, parecen razonables las palabras de Ridruejo de 1940 respecto a la endeblez de su cosmovisión política: «Para todo se contó con la fidelidad del pobre don Antonio a sus antiguos y sencillos sentimientos políticos, y digo sentimientos y no ideas porque don Antonio ideas políticas no tenía, o las que tenía no tenían forma de tales [...]» ${ }^{4}$. Los exiliados republicanos, por su parte, nunca renunciaron a su herencia. Prueba de ello será la temprana edición en 1940 de sus Obras Completas en la editorial Séneca de México, a cargo de José Bergamín, a las que seguiría otra edición en Losada en 1964 a cargo de Guillermo de Torre y Aurora de Albornoz ${ }^{5}$. En febrero de 1959 se lleva a cabo un homenaje en Collioure animado por el Partido Comunista y su política de

2 Ridruejo (1941). Sobre la actitud del conjunto del grupo Escorial hacia el poeta, puede verse el estudio de Iraviedra (2001). También Santonja (1994).

3 Ridruejo (1973).

4 Ridruejo (1941): IX.

5 De Torre y de Albornoz (1964) y de Albornoz (1993). Sobre la presencia de Antonio Machado en el franquismo, véase Rubio (1994). Sobre la vigencia de Antonio Machado en la lucha antifranquista y la Transición puede verse Muñoz Soro y García 
reconciliación nacional. Le seguirá un homenaje en Segovia y otros actos en Moscú, París y Roma en 1964, con motivo del vigesimoquinto aniversario de su muerte. En febrero de 1966 tiene lugar el homenaje nacional en Baeza frustrado por la intervención de la Guardia Civil. Ya en el inicio de la transición a la democracia, Antonio Machado se habrá de convertir en el poeta inspirador de la reconciliación y el consenso indispensables para la restablecida democracia en España.

La significación política del poeta no se ha traducido en una paralela atención a este aspecto de su obra. Entre la numerosa bibliografía machadiana, las consideraciones de carácter político en absoluto son comparables a las de carácter estrictamente literario, filosófico o hasta religioso. Y esta observación es aplicable al tema del patriotismo y el nacionalismo que ahora nos ocupa.

La notable influencia política que alcanzó Antonio Machado a lo largo de la II República y, especialmente, la Guerra Civil, y su significado como símbolo antifranquista a lo largo de la dictadura, no oculta el dato de que su formación política y la consistencia de su consiguiente cosmovisión política no se caracterizan por su solidez. Creo que lo ha visto muy bien, en paralelo a la observación antes citada de Ridruejo, el hispanista francés Serge Salaün: «La formación política de Machado es muy [...] relativa y muy personal, nada doctrinal, algo mesiánica y utópica, con resabios del idealismo esencialista decimonónico, pero este candor ideológico es quizás lo que le sitúa en un lugar aparte en la batalla política de la época y le granjea el respeto de todo el mundo» ${ }^{6}$.

Es verdad que esta debilidad de su personalidad política convive con un conjunto de valores que Antonio Machado heredó de su ambiente familiar y de su paso por la Institución Libre de Enseñanza. De su ambiente familiar hay que destacar la influencia de su abuelo y de su padre ${ }^{7}$. El primero fue catedrático de Física y Química y después catedrático de Historia Natural. Geólogo, botánico y antropólogo, tuvo además una significativa participación política como alcalde de Sevilla y gobernador de la provincia de Sevilla a lo largo del Sexenio Revolucionario. En su conformación ideológica destacan la presencia del krausismo, el darwinismo y el republicanismo. Su padre, Antonio Machado Alvarez, Demófilo, fue un destacado pionero de los estudios folkloristas en España. Su condición de krausista, republicano y masón dejaría

Fernández (2010) y Muñoz Soro (2013). Una relación de los actos y monográficos de publicaciones en homenaje al poeta en Rebollo Sánchez (2008).

6 Salaün (2006).

7 Baltanás (2006). 
profunda influencia en su hijo. A ello se podría añadir el influjo de la tertulia de Eduardo Benot a la que asistió regularmente el poeta en compañía de su hermano Manuel, y en la que tendría oportunidad de tratar a Francisco Pi y Margall y a Nicolás Estébanez, representantes como el propio Benot de la tradición del federalismo republicano.

«La Institución inició a Antonio Machado en el aprendizaje de valores morales muy característicos del espíritu institucionalista: tolerancia, respeto al trabajo, gusto por cierta austeridad de vida e incluso por cierta pobreza, ideal reformista y patriótico, rechazo de todo dogmatismo, sentido del trabajo y de la igualdad entre los hombres, amor y gusto por la verdad ${ }^{8}$. Con todo, la obra y personalidad de Antonio Machado registra una desviación del componente elitista de la Institución. Su aprecio por lo popular, su presentación como heredero de una tradición folklorista y aprendiz de las tradiciones populares, constituye una auténtica constante en su obra que le aleja de la preocupación por la formación de minorías propia del ánimo gineriano y de sus más íntimos colaboradores, una preocupación acrecentada con el paso de los años.

La falta de solidez de sus ideas políticas se refleja en el tema del patriotismo y el nacionalismo y se pone de manifiesto también en su visión de Castilla y el paisaje soriano. Pero esa ausencia de congruencia política tendrá también su reflejo en otras cuestiones colaterales a las que luego aludiré, como pueden ser la presencia de un significativo componente antisemita, su misoginia o su enemiga al republicanismo moderado.

\section{SORIA Y CASTILLA EN LA OBRA MACHADIANA}

Por lo que hace a su visión de Castilla y del paisaje soriano, su condición de entusiasta cantor de esos escenarios no impide reconocer el calado de su crítica a los mismos. En «A orillas del Duero» expresa su desolación ante un paisaje y, especialmente, ante un paisanaje que no duda en condenar:

¡Oh, tierra triste y noble,

la de los altos llanos y yermos y roquedas, de campos sin arados, regatos ni arboledas; decrépitas ciudades, caminos sin mesones, y atónitos palurdos sin danzas ni canciones que aún van, abandonando el mortecino hogar,

$8 \quad$ Sesé (1980): 34. 
como tus largos ríos, Castilla hacia la mar!

Castilla miserable, ayer dominadora,

envuelta en sus andrajos desprecia cuanto ignora?

En Campos de Castilla se incluye «Por tierras de España», una despiadada crítica hacia un sector del paisanaje soriano:

El hombre de estos campos que incendia losa pinares

y su despojo aguarda como botín de guerra,

antaño hubo raído los negros encinares,

talando los robustos robledos de la sierra...

Abunda el hombre malo del campo y de la aldea,

capaz de insanos vicios y crímenes bestiales,

que bajo el pardo sayo esconde su alma fea, esclava de los siete pecados capitales.

Los ojos siempre turbios de envidia o de tristeza, guardan su presa y llora la que al vecino alcanza;

ni para su infortunio ni goza su riqueza;

le hieren y acongojan su fortuna y maladanza.

El numen de estos campos es sanguinario y fiero;

al declinar la tarde, sobre el remoto alcor, veréis agigantarse la forma de un arquero, la forma de un inmenso centauro flechador.

Veréis llanuras bélicas y páramos de asceta

—no fue por estos campos el bíblico jardín-;

son tierras para el águila, un trozo del planeta

por donde cruza errante la sombra de Caín ${ }^{10}$.

No es entusiasmo precisamente el que se respira en a «Orillas del Duero» hacia las ciudades castellanas:

¡Oh tierra ingrata y fuerte, tierra mía!

¡Castilla, tus decrépitas ciudades!

¡La agria melancolía

que puebla tus sombrías soledades!

¡Castilla varonil, adusta tierra,

Castilla del desdén contra la suerte,

9 Machado (1989): 494. Vol. II.

10 Id., 495. 
Castilla del dolor y de la guerra, tierra inmortal, Castilla de la muerte! ${ }^{11}$.

Una crítica al paisanaje soriano que todavía se hace más hiriente en su romance «La tierra de Alvargonzález»:

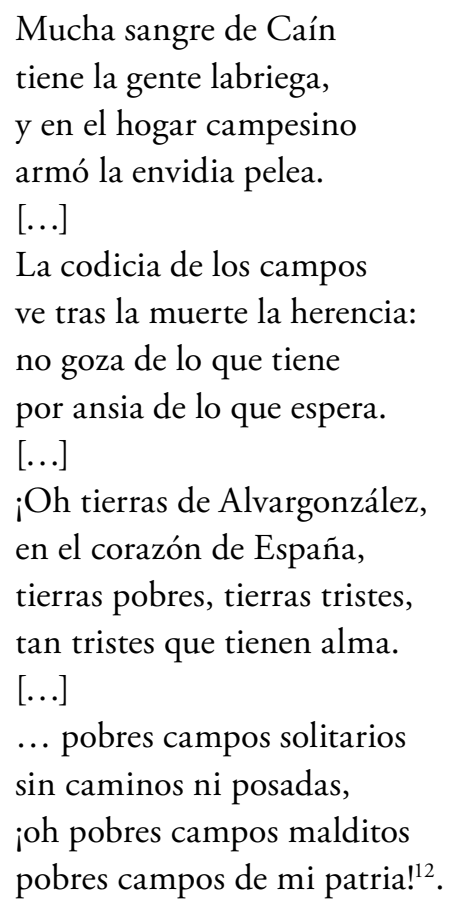

Con motivo de un recital de este romance en el Burgo de Osma hace un par de veranos, recuerdo el comentario que me hizo un asistente al mismo: «Este Machado no tenía una buena idea de nosotros, los sorianos». Un comentario que recordaba las reacciones de la prensa local a la publicación del poema "Por tierras del Duero» en Tierra Soriana ${ }^{13}$. Concretamente, escribía Santiago Gómez Santacruz: «No podemos admitir como justo el concepto que al Sr. Machado le merecen los habitantes de la Tierra del Duero, entre los cuales los habrá con los vicios que les atribuye el Sr. Machado, pero es innegable que son

\footnotetext{
Ibid., 499.

Ibid., 536.

13 Sobre este incidente y la conexión general de Antonio Machado con Soria pueden verse las colaboraciones de Martínez Laseca (2006; 2007).
} 
excepciones mismas y que en la generalidad se encuentran muchas virtudes que el poeta parece negarlas en su composición ${ }^{11}$.

Estamos en todo caso ante el mismo Antonio Machado que no se cansó a lo largo de su obra de cantar su entusiasmo por el paisaje soriano:

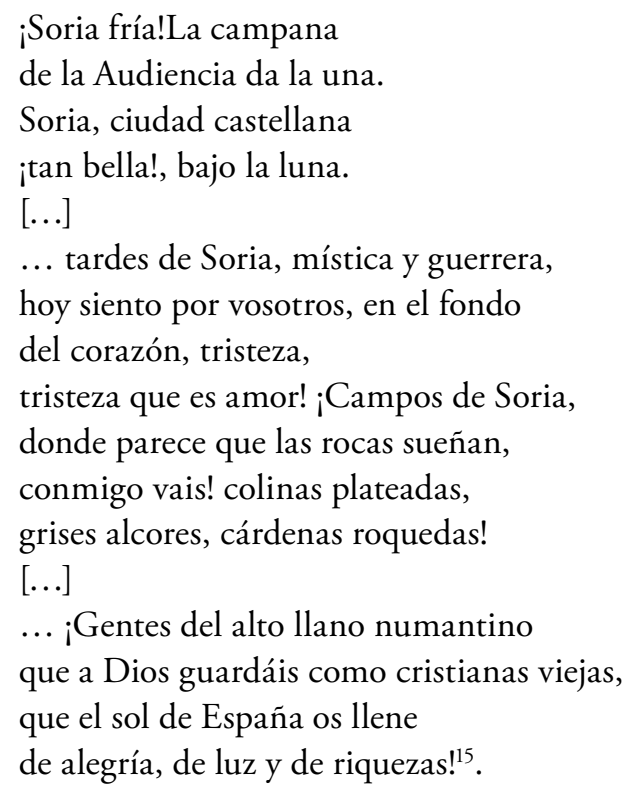

Y en el propio romance «La tierra de Alvargonzález» cambia radicalmente la perspectiva en su referencia al paisaje:
La hermosa tierra de España
adusta, fina y guerrera
Castilla de largos ríos, tiene un puñado de sierras entre Soria y Burgos como reductos de fortaleza

\footnotetext{
14 Martínez Laseca (2007): 254. El 14-1-1911 publica Tierra Soriana «Una poesía», que es una contestación a esta crítica: «Nosotros que hemos demostrado nuestros mejores cariños por Soria, y que ensalzamos sus virtudes y señalamos y señalaremos sus defectos y sus males porque los tiene, y lo patriótico es hacerlo resaltar para corregirlos, no consentiremos, como nadie que de soriano se precie, el que se acumule más injusticias sobre las que ya pesan en este país».

15 Machado (1989): 515. Vol. II.
} 
como yelmos crestonados, y Urbión es una cimera ${ }^{16}$.

En «Glosando a Ronsard y otras rimas» expresa su profunda nostalgia por un paisaje soriano que le perseguirá de por vida:

... De aquel trozo de España, alto y roquero,
hoy traigo a ti, Guadalquivir florido,
una mata de áspero romero.
Mi corazón está donde ha nacido,
no a la vida, al amor, cerca del Duero...
¡El muro blanco y el ciprés erguido ${ }^{17}$.

En 1932, contesta al anuncio del homenaje que habrá de rendirle la ciudad: «Nada me debe Soria, creo yo, y si algo me debiera sería muy poco en proporción a lo que yo le debo: el haber aprendido en ella a sentir a Castilla, que es la manera más directa y mejor de sentir a Espańa. Para aceptar tan desmedido homenaje sólo me anima esta consideración. El hijo adoptivo de vuestra ciudad ya hace años que ha adoptado a Soria como Patria ideal $»^{18}$.

Es en este mismo año cuando Antonio Machado escribe quizás su más sentido elogio de Soria y de Castilla: «Y hombres de otras tierras, que cruzamos sus páramos, no han podido olvidarla. Soria es, acaso, lo más espiritual de esa espiritual Castilla, espíritu a su vez de España entera. Nada hay en ella que asombre, o que brille y truene; todo es allí sencillo, modesto, llano» ${ }^{19}$. Y en el inicio de la Guerra Civil reafirma esta devoción por Castilla citando una vez más el dicho del pastor soriano que tanta huella habría de dejar en su ánimo: “Nadie es más que nadie”, reza un adagio de Castilla. ¡Expresión perfecta de modestia y orgullo! Sí, "nadie es más que nadie", porque a nadie le es dado aventajarse a todos, pues a todo hay quien gane, en circunstancias de lugar y tiempo. "Nadie es más que nadie" porque —y éste es el más hondo sentido de la frase-, por mucho que valga un hombre, nunca tendrá valor más alto que el valor de ser hombre. Así habla Castilla, un pueblo de señores, que siempre ha despreciado al señorito $»^{20}$. Una devoción que continúa en los escritos, declaraciones y discursos a lo largo de la Guerra Civil.

\footnotetext{
Ibid., 523.

Ibid., 662.

Ibid., 1800. Vol. III.

Ibid., 1801.

Ibid., 2164. Vol. IV.
} 
Esta ambivalencia por el contexto social y cultural en que toma cuerpo su adorado paisaje soriano y castellano, esta simultánea presencia de Caín y Abel, tiene su reflejo en su visión poética de España. En primer lugar, su crítica a la España tradicional:

Este hombre no es de ayer ni es de mañana, sino de nunca; de la cepa hispana no es el fruto maduro ni podrido, es una fruta vana de aquella España que pasó y no ha sido, esa que hoy tiene la cabeza cana ${ }^{21}$.

En «El mańana efímero» remata esta crítica:

La España de charanga y pandereta, cerrado y sacristía, devota de Frascuelo y de María, de espíritu burlón y de alma quieta, ha de tener su mármol y su día, su infalible mańana y su poeta.

... Esa España inferior que ora y bosteza, vieja y tahúr, zaragatera y triste: esa Espańa inferior que ora y embiste, cuando se digna usar de la cabeza, aún tendrá luengo parto de varones amantes de sagradas tradiciones ${ }^{22}$.

En «Proverbios y cantares» insiste en esta descalificación de la España tradicional:

- Nuestro español bosteza, ¿Es hambre? ¿Sueño? ¿Hastío?

Doctor, ¿tendrá el estómago vacío?

- El vacío es más bien en la cabeza ${ }^{23}$.

21 Ibid., 560. Vol. II.

22 Ibid., 567.

23 Ibid., 581. 
Una crítica que no impide la expresión de esperanza en una nueva España a lo largo de su obra poética:

Mas otra España nace,

la España del cincel y de la maza.

con esa eterna juventud que se hace

del pasado macizo de la raza.

Una España implacable y redentora,

España que alborea

con una hacha en la mano vengadora,

España de la rabia y de la idea ${ }^{24}$.

En «Proverbios y cantares» escribe:
Ya hay un español que quiere
vivir y vivir empieza,
entre una España que muere
y otra España que bosteza.
Españolito que vienes
al mundo, te guarde Dios.
Una de las dos Españas
ha de helarte el corazón ${ }^{25}$.

En su «Elogio a D. Francisco Giner los Ríos» expresa su confianza en el futuro de España:
Allí el maestro un día sońaba un nuevo florecer de España ${ }^{26}$.

Una confianza que reitera en su recuerdo a Azorín:

¡Oh tú, Azorín, escucha: España quiere surgir, brotar, toda una España empieza! ¿Y ha de helarse en la España que se muere? ¿Ha de ahogarse en la España que bosteza? ${ }^{27}$

\footnotetext{
Ibid., 568.

Ibid., 582.

Ibid., 588.

7 Ibid., 593.
} 


\section{LA AMBIVALENCIA RESPECTO A UN SENTIMIENTO PATRIÓTICO}

En la obra en prosa de Antonio Machado el sentimiento patriótico tiene dos tiempos bien diferenciados: el anterior y el posterior al inicio de la Guerra Civil. Con anterioridad a 1936 el sentimiento patriótico en él resulta manifiestamente contenido. En 1923 no oculta su falta de confianza en España: «España cae en cuatro pies. ¿Se levantará? Probablemente encontrará cómoda la postura y permanecerá en ella largo tiempo $»^{28}$. Una desconfianza que todavía se hará más explícita en 1924: «Solo España, el país más estúpido del planeta, puede cerrar los ojos y dejarse llevar al derrumbadero por gente tan menguada. A todo esto se puede seguir llamando "revolución desde arriba" ${ }^{29}$.

Estas manifestaciones de distanciamiento respecto a la realidad española no son obstáculo para la primera definición de un sentimiento patriótico en clara conexión con el ánimo noventayochista. En un artículo en la prensa soriana de 1908 expresa rotundamente su abandono de un patriotismo tradicional a favor de un patriotismo de progreso:

Por lo pronto, nuestro patriotismo ha cambiado de rumbo y de cauce. Sabemos ya que no se puede vivir ni del esfuerzo, ni de la virtud, ni de la fortuna de nuestros abuelos; que la misma vida parasitaria no puede nutrirse de cosa tan inconsistente como el recuerdo; que las más remotas posibilidades del porvenir distan menos de nosotros que las realidades muertas en nuestras manos. Luchamos por libertarnos del culto supersticioso del pasado.

[...] Somos los hijos de una tierra pobre e ignorante, de una tierra donde todo está por hacer. He aquí lo que sabemos.

[...] Sabemos que la patria es algo que se hace constantemente y se conserva sólo por la cultura y el trabajo. El pueblo que la descuida o la abandona, la pierde, aunque sepa morir $^{30}$.

Una idea que conecta con su visión de la patria en una carta a José Ortega y Gasset de 1912: «Muy sinceramente le digo a V. que me encanta eso de que la patria sea lo que se tiene que hacer. No lo hubiera yo nunca formulado de un modo tan sencillo y admirable; pero esa patria la he sentido muchas veces con todo mi corazón $»^{31}$. Una identificación con la generación del 98 que el poeta hace explícita en una entrevista concedida en tiempos de guerra: «La

\footnotetext{
Ibid., 1289. Vol. III.

Ibid., 1316.

Ibid., 1483.

Ibid., 1512.
} 
llevada y traída y calumniada generación del 98, en la cual se me incluye siguió hablando el poeta, un poco abstraído, sereno y alegre: con esa alegría tan seria de Machado y del español — ha amado a España como nadie, nos "duele Espańa» - como dijo y dijo bien, ese donquijotesco D. Miguel de Unamuno- como a nadie ha podido dolerle jamás patria alguna " ${ }^{32}$. Se trataría en definitiva de la experiencia de un patriotismo crítico al que se refirió con especial énfasis Manuel Tuñón de Lara: «Sin embargo, es probablemente Antonio Machado el escritor que permanecerá fiel hasta su muerte a ese tema de «España» concebido como exigencia crítica y de superación, que compartió con aquellos hombres entre los 25 y 30 años [...]. La «españolidad» de Machado supone la severidad para consigo, garantía del amor nacional. Puesto que a nadie se le ocurre ocultar las enfermedades del ser querido, sino poner todo en obra para curarlas $\aleph^{33}$.

Hay, sin embargo, en el Machado anterior a la Guerra Civil una visión del patriotismo que desborda los planteamientos de Unamuno, Baroja o Azorín sobre el tema, tal como veremos a continuación.

Por estos años manifestará una reticencia a la idea de España en la que se pone de manifiesto, con carácter complementario, una misoginia muy acusada en el conjunto de su obra. Así, en una carta a Juan Ramón Jiménez de 1913, esa reticencia a la idea de España se une a la supuesta condición femenina del país: «Todo esto es femenino. España es hembra. El argumento de los pantalones carece de valor en un país donde todo negocio de alguna trascendencia lo rematan las mujeres a escobazos. Esta es la realidad española» ${ }^{34}$.

Tres escritos de estos ańos de Juan de Mairena insisten en el tema: «Donde la mujer suele estar, como en España — decía Juan de Mairena-, en su puesto, es decir, en su casa, cerca del fogón y consagrada al cuidado de los hijos, es ella la que casi siempre domina, hasta imprimir el sello de su voluntad a la sociedad entera ${ }^{35}$. En el segundo, Juan de Mairena se pronuncia abiertamente por la discriminación política de la mujer: «Conviene que la mujer permanezca abacia, carente de voz y voto en la vida pública, no sólo porque la política sea, como algunos pensamos, actividad esencialmente varonil, sino porque la influencia política de la mujer convertiría muy en breve el gobierno de los viejos en gobierno de las viejas, y el gobierno de las viejas es gobierno de las brujas. Y esto es lo que a toda costa conviene evitar ${ }^{36}$. En el tercero, realiza

\footnotetext{
Ibid., 1937. Vol. IV.

33 Tunón de Lara (1997): 39.

34 Machado (1989): 1.523. Vol. III.

35 Ibid., 1980. Vol. IV.

36 Ibid., 2027.
} 
un claro comentario despectivo hacia las mujeres: «Lo que hace realmente angustiosa la lectura de algunas novelas, como en general la conversación de las mujeres, es la anécdota boba, el detalle insignificante, el documento crudo, horro de toda elaboración imaginativa, reflexiva, estética» ${ }^{37}$.

La ambivalencia respeto a la valoración de la realidad española se pone claramente de manifiesto en su autobiografía de 1913: «Tengo un gran amor a Espańa y una idea completamente negativa. Todo lo español me encanta y me indigna al mismo tiempo ${ }^{38}$. Afirmación a la altura de sus dudas del momento acerca de la condición de lo español: «Si las escuelas no han de ser ineficaces —y bien pudieran serlo aun duplicando su número-, han de servir para formar españoles. Pero ¿sabemos nosotros lo que es o puede ser un español?»»39.

De 1914 a 1934 es posible localizar manifestaciones de Antonio Machado en que se cuestiona directamente el valor del patriotismo. En una carta a Miguel de Unamuno, la guerra del 14 es pretexto para el cuestionamiento del mismo: «Esta guerra me parece tan trágica y terrible como falta de nobleza y de sentimientos, que nos parecían santos y que son, en realidad, criminales, inhumanos. Yo empiezo a dudar de la santidad del patriotismo $»^{40}$. En otra carta al mismo destinatario, insiste en 1918 en la misma idea: «Porque el cainismo perdura, a pesar de Cristo; pasa del individuo a la familia, a la casta, a la clase y hoy lo vemos extendido a las naciones, en ese sentimiento tan fuerte y tan vil que se llama patriotismo. Sólo los rusos — ibendito pueblo! - me parecen capaces de superarlo por un sentimiento más noble y universal» ${ }^{41}$.

Es al mismo admirado Miguel de Unamuno al que manifiesta en $1921 \mathrm{su}$ desconfianza en el porvenir de España: «Mi proximidad a Madrid y más frecuente residencia en la corte me ha dado, a cambio de algunas ventajas, una mayor desconfianza del porvenir de España. Es mucha Boecia esta villa coronada. La guerra trajo un cierto incremento de riqueza (hija del robo, no de la industria) y esta riqueza se manifiesta hasta ahora en un aumento de bestialidad, de egoísmo, de materialidad $»^{42}$.

En su proyecto de discurso de ingreso en la Academia Española de la Lengua, plantea Antonio Machado la caducidad del sentimiento patriótico: «¿Cuántos siglos durará el sentimiento de la patria? Y aun dentro de un mismo ambiente sentimental ¡qué variedad de grados y de matices! Hay quien llora al

\footnotetext{
Ibid., 2038.

Ibid., 1524. Vol. III.

Ibid., 1529.

Ibid., 1558.

Ibid., 1600.

Ibid., 1621.
} 
paso de una bandera, quien se descubre con respeto, quien la mira pasar indiferente, quien siente hacia ella antipatía, aversión. Nada tan voluble y tan vario como el sentimiento" ${ }^{43}$. Y en una carta a Ramiro de Maeztu de 1934 acusando el envío de un ejemplar de Defensa de la Hispanidad, le pone en guardia al escritor alavés acerca de la escasa movilización que habrá de corresponder a una llamada de signo españolista: «Pero por eso mismo no es fácil que salgamos por el mundo a darnos pisto de espańoles, y si sacamos la espada, antes será por Dios o por el diablo, que por España. Porque España ha sido siempre muy poca cosa para un español. Tal vez sea ésta la causa de nuestra decadencia actual y de nuestra pasada grandeza. Aún todavía, si habla usted de las banderas de Cristo, encontrará usted quien le siga, con la bandera espańola no entusiasmará a nadie» ${ }^{44}$.

En todo caso, Juan de Mairena avanza en Sentencias, donaires, apuntes y recuerdos de un profesor apócrifo una idea sugerente: la distinción entre el amor a España y el sentimiento patriótico:

Yo siempre os aconsejaré que procuréis ser mejores de lo que sois, de ningún modo que dejéis de ser españoles. Porque nadie más amante que yo ni más convencido de las virtudes de nuestra raza. Entre ellas debemos contar la de ser muy severos para juzgarnos a nosotros mismos, y bastante indulgentes para juzgar a nuestros vecinos. Hay que ser español, en efecto, para decir las cosas que se dicen contra Espańa. Pero nada advertiréis en esto que no sea natural y explicable.

[...] Los que hablan de Espańa como de una razón social, que es preciso a toda costa acreditar y defender en el mercado mundial, éstos para quienes el reclamo, el jaleo y la ocultación de vicios son deberes patrióticos, podrán merecer, yo lo concedo, el título de buenos patriotas; de ningún modo el de buenos españoles. [...] Espańa no ha peleado nunca por orgullo nacional, ni por orgullo de raza, sino por orgullo humano o por amor de Dios, que viene a ser lo mismo. De esto hablaremos más despacio otro día ${ }^{45}$.

\section{EL GIRO EN LA GUERRA CIVIL}

Esta actitud reticente ante el patriotismo se va a modificar sustancialmente con el inicio de la Guerra Civil. Antonio Machado va a ver en la causa

\footnotetext{
43 Ibid., 1784

44 Ibid., 1815.

45 Ibid., 1960. Vol. IV.
} 
de una nación española víctima de la invasión extranjera con el soporte de un puñado de traidores del interior el motivo fundamental de legitimación de una República que, sin embargo, no duda en ocasiones en calificar de III República a partir de las elecciones de febrero de 1936 y que parece dar a entender una tesis apoyada por los sublevados el 18 de julio de 1936: las elecciones ganadas por el Frente Popular pondrían fin a una República democrática para dar paso a una República revolucionaria que poco tendría que ver con la surgida el 14 de abril de 1931.

De conformidad con este nuevo registro, la patria pasa a ser la invocación de unos señoritos dispuestos a venderla contra la actitud de un pueblo que, sin nombrarla siquiera, está dispuesto a comprarla y salvarla con su sangre (carta a David Vigodsky, entrevista con J. Orozco de 1-5-1937, «Juan de Mairena póstumo", marzo de 1937, entre otras referencias a una idea repetida en sus escritos de guerra).

La Guerra Civil ha dejado para Antonio Machado de tener el carácter de tal para convertirse en una guerra de invasión y de traición: «La Guerra Civil, tan desigual éticamente, pero, al fin, entre españoles, ha terminado hace muchos meses. España ha sido vendida al extranjero por hombres que no pueden llamarse españoles: quien vende a su patria se desnaturaliza y ha de sobreentenderse que renuncia a su patria para buscar cobijo en la patria del comprador ${ }^{46}$. En la misma idea insiste al ańo siguiente:

La guerra actual tuvo, en sus comienzos, una apariencia de Guerra Civil, de una guerra entre españoles divididos por ideologías encontradas. Esta apariencia no ha podido mantenerse, porque uno de los bandos, el llamado fascista, ha vendido a la patria común, con lo cual ipso facto, perdió su nacionalidad. Frente a ellos, los traidores y los invasores unidos, frente a su máquina de guerra, a ese poder demoníaco y abominable consagrado a la ambición y al crimen, está España con su magnífico Ejército popular, afirmando su voluntad de perdurar en la historia, su derecho a conservar la integridad de su territorio y a disponer libremente de su futuro ${ }^{47}$.

Esta visión de la Guerra Civil como una batalla librada por la causa republicana contra la agresión exterior, es la que le permitirá a Antonio Machado coincidir con la movilización de la historia que llevan a cabo diferentes instancias republicanas en defensa de su causa y a subrayar el paralelismo entre este enfrentamiento y la guerra de Independencia: «Si, mutatis mutandis, el trance

46 Ibid., 2234.

47 Ibid., 2255. 
de la Espańa de entonces era el de la España actual; entonces como hoy se luchaba por la integridad de nuestra patria y por el derecho de los españoles a perdurar en la historia. Sí, no lo dudéis, el guerrillero de ayer, el más ilustre sin duda, de todos los guerrilleros de su tiempo, abrazaría hoy fraternalmente, con viril efusión a muchos capitanes no menos egregios de nuestros días ${ }^{48}$. Y conmemorando el 2 de mayo en 1938, escribe: «Alguien ha señalado con certero tino su semejanza [la toma del Cuartel de la Montańa], o mejor dicho su equivalencia, con la gloriosa jornada del 2 de mayo de 1808. En ambos días se inicia en verdad un levantamiento popular que había muy pronto de convertirse en defensa de la patria invadida y en tenaz campaña por la independencia española ${ }^{49}$. Y no sólo la guerra de Independencia es evocada en defensa de la causa republicana: el propio Cid Campeador será presentado como antecedente de los defensores de España contra una invasión extranjera que ha roto la existencia de una comunidad nacional capaz de albergar a leales y rebeldes.

\section{LOS NACIONALISMOS PERIFÉRICOS}

Su visión de la cuestión nacional quedaría incompleta sin una referencia a la visión por el poeta de los nacionalismos periféricos de Espańa. De su escasa simpatía por el catalanismo político da cuenta una referencia a Cambó de 1922 como «el cuervo catalán». Pero es en una carta a Guiomar en los años republicanos donde manifiesta abiertamente su crítica al nacionalismo catalán:

La cuestión de Cataluña, sobre todo, es muy desagradable. En esto no me doy por sorprendido, porque el mismo día que supe el golpe de mano de los catalanes lo dije: «Los catalanes no nos han ayudado a traer la República, pero ellos serán los que se la lleven». Y en efecto, contra esta República, donde no faltan hombres de buena fe, milita Cataluńa. Creo con D. Miguel de Unamuno que el Estatuto es, en lo referente a la Hacienda, un verdadero atraco, y en lo tocante a enseñanza algo verdaderamente intolerable. Creo, sin embargo, que todavía cabe una reacción a favor de Espańa, que no conceda a Cataluña sino lo justo: una moderada autonomía, y nada más. Ortega y Gasset ha dicho a mi juicio algo muy atinado sobre la psicología del catalanismo. Sánchez Román ha estudiado muy bien el aspecto jurídico de la cuestión. Veremos. Yo todavía no he perdido todas las esperanzas ${ }^{50}$.

\footnotetext{
$48 \quad$ Ibid., 2.243

49 Ibid., 2.252.

50 Ibid., 1750. Vol. III.
} 
En algún momento de los años republicanos, Juan de Mairena se pronuncia a favor de un principio de lealtades compartidas, en plena coherencia con el espíritu que anima al Estado integral republicano: «Cierto es, señores, que la mitad de nuestro corazón se queda en la patria chica; pero la otra mitad no puede contenerse en tan estrechos límites; con ella invadimos amorosamente la totalidad de nuestra gloriosa España. Y si dispusiéramos de una tercera mitad, la consagraríamos íntegramente al amor de la humanidad entera $»^{51}$.

Su entusiasmo por Castilla o su conciencia andaluza nunca se tradujo en la defensa de sus balbuceantes regionalismos. Ya en plena Guerra Civil, en 1937, escribe al respecto:

De aquellos que se dicen gallegos, catalanes, vascos, extremeńos, castellanos etc., antes que españoles, desconfiad siempre. Suelen ser españoles incompletos, insuficientes, de quienes nada grande puede esperarse.

- Según eso, amigo Mairena - habla Tortolez en un café de Sevilla—, un andaluz andalucista será también un español de segunda clase.

—En efecto — respondió Mairena-: un español de segunda clase y un andaluz de tercera ${ }^{52}$.

En plena Guerra Civil recuerda Machado el significado de la literatura catalana y tiene un gesto de proximidad a la lengua catalana: « $i$ Qué bien nos entendemos en lenguas maternas diferentes, cuando decimos, de este lado del Ebro, bajo un delirio de iniquidades: «Nosotros no hemos vendido nuestra España». Y el que esto se diga en catalán como en castellano en nada asegura ni acrecienta su verdad» ${ }^{53}$. Una manifestación de afecto a Cataluña que no hace suponer, sin embargo, una rectificación de su opinión crítica hacia los nacionalismos periféricos.

\section{COMPONENTES CONTRADICTORIOS DE SU COSMOVISION POLÍTICA}

Decía antes que en Antonio Machado hay algunos componentes de su cosmovisión política que sorprenden y sobre los que se ha llamado escasamente la atención. A la misoginia de nuestro hombre hemos tenido ya oportunidad de aludir a la hora de subrayar el carácter femenino atribuible a la vida española. El antisemitismo tiene una presencia acusada en su obra. Carlos Serrano señaló que

\footnotetext{
51 Ibid., 2024. Vol. IV.

52 Ibid., 2335.

53 Ibid., 2475.
} 
se trata más de un antisemitismo cultural que de un antijudaismo racial ${ }^{54}$. Aunque aceptemos la oscura distinción, lo cierto es que Machado manifiesta rotundamente en 1927 ese antisemitismo para descalificar, por cierto, la obra de Marx: "Carlos Marx, señores — ya lo decía mi maestro-, fue un judío alemán que interpretó a Hegel de una manera judaica, con su dialéctica materialista y su visión usuraria del futuro. ¡Justicia para el innumerable rebaño de los hombres; el mundo para apacentarlo! Con Marx, señores, la Europa, apenas cristianizada, retrocede al viejo Testamento ${ }^{55}$. Y en la misma idea insistirá Juan de Mairena:

El marxismo, señores, es una interpretación judaica de la Historia. El marxismo, sin embargo, ahorcará a los banqueros y perseguirá a los judíos. ¿Para despistar? En el fondo, también es judaica la persecución a los judíos. Y no solamente porque ella supone la previa existencia del pueblo deicida, sino porque además, y sobre todo, ¿¿Hay nada más judaico que la ilusión de pertenecer a un rebaño "privilegiado" para perdurar en el tiempo? "Aquí no hay más pueblo elegido que el nuestro». Así habla el espíritu mosaico a través de los siglos ${ }^{56}$.

Pero el reproche de judaísmo sirve igualmente para descalificar a los rebeldes en 1937: «Los generales se sublevaron por los treinta dineros de Judas, en primer lugar. En segundo lugar [...] por la rencorosa frivolidad, no menos judaica, que no mide nunca las consecuencias de sus actos ${ }^{57}$. El papel liberador de Rusia no será ajeno a la presencia en ella del recelo antijudío: «Sólo el ruso, a juzgar por su gran literatura, nos parece vivir en cristiano, quiero decir auténticamente inquieto por el mandato del amor de sentido fraterno, emancipado de los vínculos de sangre, de los apetitos de la carne, y del afán judaico de perdurar, como rebaño, en el tiempo $»^{58}$.

Lo cierto es que ignorando los posibles orígenes judíos de los Machado portugueses, nuestro autor realiza esta concesión al ambiente ideológico del momento, un ambiente del que está libre, sin embargo, el grueso del progresismo español.

En conexión con este componente antisemita en su obra hay que poner su simpatía por Rusia mejor aún que por la URSS y su distancia, siempre mantenida, con la ortodoxia marxista. En 1922 escribe en Los complementarios: «Falta hoy a Rusia metafísica propia, y una de las causas del fracaso de su gran

\footnotetext{
Serrano (1990).

Machado (1989): 1.927. Vol. IV.

Ibid., 2108.

Ibid., 2178.

Ibid., 2219.
} 
revolución acaso sea el desmedido tributo que las mentalidades directoras de Rusia rinden necesariamente al pensamiento alemán, al determinismo económico de Carlos Marx ${ }^{59}$. En 1934, en una entrevista con Alardo Prats, explicita su rechazo de la propaganda empleada por la inicial literatura de la revolución soviética: «Todo lo que he leído de la literatura de Rusia nueva es francamente superficial, y de ninguna manera se puede comparar con la producción de los viejos maestros rusos ${ }^{60}$.

El antimarxismo de Antonio Machado, del que hay abiertas manifestaciones incluso en los años de la guerra, no supone ninguna contradicción con la orientación de la propaganda y la política informativa que inspira a los dirigentes republicanos y a los propios dirigentes comunistas. Antonio Machado pasaría así a representar más fielmente la política estalinista de defensa para España de un orden democrático en lugar de una revolución socialista. Máxime cuando Machado sabe combinar su distancia del marxismo con su fervor por la Unión Soviética:

Moscú, en cambio - resumamos en este claro nombre toda la vasta organización de la Rusia actual—, aunque salude con el puño cerrado, es la mano abierta y generosa, el corazón hospitalario para todos los hombres libres, que se afanan por crear una forma de convivencia humana, que no tiene sus límites en las fronteras de Rusia. Desde su gran revolución, un hecho genial surgido en plena guerra entre naciones, Moscú vive consagrado a una labor constructora, que es una empresa gigante de radio universal ${ }^{61}$.

Una Rusia que ha sabido trascender su propia condición marxista: «Mi tesis es ésta: la Rusia actual, que a todos nos asombra, es marxista, pero es mucho más que marxismo. Por eso el marxismo que ha traspasado todas las fronteras y está al alcance de todos los pueblos, es en Rusia donde parece hablar a nuestro corazón ${ }^{62}$. Una Rusia, en definitiva, que ha sabido hacerse acreedora de la amistad española: «Nada tan español, nada tan popular — reparadlo bien-, nada tan sinceramente nuestro como esa honda simpatía, como ese amor fraterno que siente hoy España, la España auténtica, por el pueblo ruso y por los hombres de otros pueblos que han venido a verter su sangre por una causa humana, generosa y desinteresadamente, al lado nuestro" ${ }^{63}$.

\footnotetext{
59 Ibid., 1233. Vol. III.

60 Ibid., 1812.

61 Ibid., 2217. Vol. IV.

62 Ibid., 2221

63 Ibid., 2264.
} 
Otra línea del discurso político machadiano es la de su hostilidad al republicanismo moderado. Ya en el pasado, Machado ha hecho objeto de su crítica al Partido Reformista. En Sentencias, donaires, apuntes y recuerdos de un profesor apócrifo Juan de Mairena dirige su crítica expresamente al republicanismo histórico: «!Ojo al sedicente republicanismo histórico, ese fantasma de la primera República! Porque los enemigos de esta segunda habrán de utilizarlo, como los griegos lo utilizaron aquel caballo de madera, en cuyo vientre penetraron en Troya los que habrían de abrir sus puertas y adueñarse de su ciudadela ${ }^{64}$. Pero es en 1937 cuando concreta su crítica en el proyecto centrista de Alejandro Lerroux: «[...] veréis que es un hombre profundamente viejo, un alma decrépita de ramera averiada y reblandecida, el llamado Lerroux, quien se encarga de acarrear a ella, de amontonar sobre ella — ¡nuestra noble República! - todos los escombros de la rancia política en derribo, toda la cochambre de la inagotable picaresca española. A esto llamaba el ensanchar la base de la República»" ${ }^{65}$. Resulta llamativa esta explícita condena del intento más positivo del republicanismo radical por ampliar el número de los defensores y de los identificados con el régimen republicano.

Es significativo igualmente el distanciamiento de Antonio Machado del mundo urbano, del supuesto refugio del progreso y de la modernidad. En su poesía «En tren» recogida en Campos de Castilla pone de manifiesto el distanciamiento genérico de las ciudades:

$$
\begin{aligned}
& \text { ¡Este placer de alejarse! } \\
& \text { Londres, Madrid, Ponferrada, } \\
& \text { tan lindos...para marcharse. } \\
& \text { Lo molesto es la llegada }{ }^{66} \text {. }
\end{aligned}
$$

Su apócrifo Abel Infanzón escribe en Los complementarios su intencionado elogio de Sevilla sin sevillanos:

$$
\begin{aligned}
& \text { Sevilla, y su verde orilla, } \\
& \text { sin toreros ni gitanos, } \\
& \text { Sevilla, sin sevillanos, } \\
& \text { ¡oh maravilla! } \text { '77 }^{\text {oh }}
\end{aligned}
$$

\footnotetext{
Ibid., 2085.

Ibid., 2191.

Ibid., 509. Vol. II.

Ibid., 1273. Vol. III.
} 
Una crítica a la que acompaña en lugar destacado la Granada en que ha sido asesinado García Lorca: «Y es que Granada, pienso yo, una de las ciudades más bellas del mundo y cuna de españoles ilustres, es también — todo hay que decirlo- una de las ciudades mas beocias de España, más entontecidas por su aislamiento y por la influencia de su aristocracia degradada y ociosa, de su burguesía irremediablemente provinciana ${ }^{68}$.

De esta actitud se salva el Madrid de guerra, que no el Madrid del pícaro y el cucañista anterior a 1936:

\author{
¡Madrid, Madrid! ¡Qué bien tu nombre suena, \\ rompeolas de todas las Españas!, \\ la tierra se desgarra, el cielo truena, \\ tu sonríes con plomo en las entrañas ${ }^{69}$.
}

Una admiración por el Madrid combatiente que reitera en 1937: «Madrid ha sabido ser España. España entera, que es la España leal al Gobierno de nuestra Gloriosa República. Luchando sin tregua contra los traidores de dentro y los invasores de fuera. Madrid no tuvo una hora de vacilación, de desconfianza o de cobardía: ni siquiera un momento de jactancia en que gritase ¡Viva Madrid! Porque siempre ha gritado ¡Arriba el Pueblo! ${ }^{70}$.

\title{
VII. UNA OBSERVACIÓN SOBRE EL TEATRO MACHADIANO
}

Una palabra final sobre el teatro que Antonio Machado cultivó con éxito con su hermano Manuel. En principio, y para el tema que nos ocupa, se trata de una cuestión poco relevante. En primer lugar, porque la compenetración entre ambos hermanos, hace tarea casi imposible distinguir la contribución específica de Antonio a esta labor dramática. Por supuesto que en el teatro machadiano es visible la huella de la obra en verso y en prosa de Antonio. Lo que no es tan fácil, al decir de los expertos en esta obra teatral, es atribuir estas referencias a uno de los hermanos ${ }^{71}$. En todo caso, el conjunto de la obra teatral machadiana matiza, entre otras cuestiones, la propensión hacia la

\footnotetext{
Ibid., 2182. Vol. IV.

Ibid., 833. Vol. II.

Ibid., 2196. Vol. IV.

1 Entre la amplia obra sobre el teatro de los hermanos Machado, pueden destacarse los trabajos de Sanmartín (2010); Baltanás (2010), y las introducciones a cargo de Chicharro en Machado y Machado (1991; 1992; 2005; 2008).
} 
misoginia que antes seńalaba. Los personajes femeninos de sus obras tienen una firme personalidad, acaso más acusada que las de sus protagonistas masculinos. El tema del patriotismo y el nacionalismo apenas asoma en una producción teatral dominada por el tema amoroso ${ }^{72}$. Un contenido abiertamente político no es visible sino en La prima Fernanda, obra en que el tema que nos ocupa no tiene presencia. En La Lola se va a los puertos y La duquesa de Benamejí hay una evocación del mundo andaluz que puede encajar con la movilización nacional de inspiración más conservadora. No en balde, ambas obras serían llevadas al cine del franquismo en sendas producciones de CIFESA. La última obra dramática de los Machado, El hombre que murió en la guerra, ofrece un trasfondo político de signo pacifista que es en todo caso ajeno a la cuestión nacional.

\section{CONCLUSIÓN}

Tengo la impresión de que la presente aproximación a la presencia del patriotismo y el nacionalismo y, en general, al conjunto de las ideas políticas de Antonio Machado, pueden proyectar una imagen cuestionadora del poeta. El respeto a su persona me veda adentrarme en otros temas que habrían de contribuir a ese cuestionamiento. Creo, en todo caso, que puede concluirse, como señalaba Jorge Guillén, que estamos ante un personaje complejo: «Sin embargo, aquel personaje - que quiere ser muy sencillo - resulta a la larga muy complejo, mucho más complejo de lo que parece a primera vista y en su leyenda y su mito, imágenes siempre simplificadas» ${ }^{73}$.

A lo largo de la Guerra Civil no hay un signo de compasión o de solidaridad con las víctimas del proceso revolucionario desencadenado en el bando republicano. Es verdad que las circunstancias eran poco propicias para este tipo de manifestaciones que, en todo caso, no dejan huella en su amplia obra de los ańos de guerra. En cuanto a su identificación general con la causa republicana a lo largo de la Guerra Civil, es indudable su coherencia con la trayectoria de Machado en los años anteriores. No por ello debe echarse en saco roto la explicación de esta actitud, como la de tantos espańoles, por razones estrictamente geográficas. La actitud de su hermano Manuel al que el levantamiento del 36 sorprende en Burgos, resulta un dato no despreciable al respecto. La Guerra Civil puede ser también la responsable de ciertas exageraciones retóricas en el tema de su patriotismo y conciencia nacional. El clima de

72 Machado y Machado (1991; 1992; 2005; 2008).

73 Guillén (1977). 
excitación y de crispación que caracteriza a una coyuntura trágica como una guerra civil no es desde luego un buen marco para la reflexión política o de cualquier otro género.

De su tristeza, de su propensión melancólica, dejan rotundo testimonio las memorias de su hermano José ${ }^{74}$. Por lo que hace al tema que nos ha ocupado en este artículo, creo que puede concluirse la presencia de una actitud contradictoria, oscilante entre el interés y el desapego por una conciencia patriótica. Es la misma presencia de Caín y Abel en la descripción del paisaje soriano. El lector tiene la impresión de que con el patriotismo, Antonio Machado ha encontrado la tecla que le permite su identificación con la República, soslayando otros temas de naturaleza para él más complicada ${ }^{75}$. Pero por debajo de todo ello, sobresale una excelente condición de poeta y escritor. Una condición que no puede verse cuestionada por otros aspectos menos positivos de su obra.

\section{Bibliografía}

Albornoz, A. de (1993). Presencia de Antonio Machado en la España Peregrina. En P. L. Ávila (ed.). Antonio Machado hacia Europa (pp. 233-241). Madrid: Visor Libros.

Aubert, P. (1994). "Gotas de sangre jacobina». Antonio Machado republicano. En P. Aubert (ed.). Antonio Machado hoy (pp. 309-361). Madrid: Casa de Velázquez.

Baltanás, E. (2006). Los Machado. Una familia, dos siglos de cultura española. Sevilla: Fundación J. M. Lara.

- (2010). La obra común de los hermanos Machado. Sevilla: Renacimiento.

Gómez Molleda, D. (1992). La España de la concordia en Machado. En J. L. García Delgado y J. M. a Serrano Sanz (coords.). Economía española, cultura y sociedad: homenaje a Juan Velarde Fuertes ofrecido por la Universidad Complutense (pp. 473-488). Madrid: Eudema Universidad.

Guillén, J. (1977). El apócrifo Antonio Machado. En J. Angeles (ed.). Estudios sobre Antonio Machado (pp. 217-230). Barcelona: Ariel.

74 Machado (1999).

75 En esta línea me parecen sugerentes las palabras de Dolores Gómez Molleda (1992): «Permítaseme subrayar que el tópico insistentemente repetido en sus alocuciones, discursos y declaraciones sobre la guerra civil como guerra de independencia, encierra, a mi modo de ver, un significado especial a este respecto. Me atrevo a pensar que, precisamente, trata con él de escabullir los planteamientos de los partidos proletarios que le asediaron, como sabemos, para pedirle manifestaciones a favor de su "causa", como causa de clase. Y que, a la vez, este tópico le sirvió al poeta de coartada para legitimar ante otros sectores de opinión su postura». 
Iraviedra, A. (2001). El poeta rescatado. Antonio Machado y la poesía del Grupo Escorial. Madrid: Biblioteca Nueva.

Machado, A. (1989). Obras Completas. Madrid: Espasa-Calpe y Fundación Antonio Machado.

— y Machado, M. (1991). Desdichas de la fortuna o Julianillo Valcárcel y Juan de Mañara. Ed. de Dámaso Chicharro. Madrid: Espasa Calpe.

(1992). Las adelfas y La Lola se va a los puertos. Ed. de Dámaso Chicharro. Madrid: Espasa Calpe.

- (2005). La prima Fernanda y La duquesa de Benamejí. Ed. de Dámaso Chicharro. Madrid: Espasa Calpe.

- (2008). El hombre que murió en la guerra. Ed. de Dámaso Chicharro. Madrid: Espasa Calpe.

Machado, J. (1999). Últimas soledades del poeta Antonio Machado: recuerdos de su hermano José. Madrid: Ed. de la Torre.

Martínez Laseca, J. M. (2006). Antonio Machado. Su paso por Soria. Soria: Diputación de Soria.

- (2007). Antonio Machado, casi unas memorias. Soria: El Mundo, Diario de Soria.

Muńoz Soro, J. (2013). Despojos despojados. Los intentos de repatriación de los restos de Antonio Machado durante el franquismo. Cercles. Revista d'Història Cultural, 16, 123-145.

— y García Fernández, H. (2010). Poeta rescatado, poeta del pueblo, poeta de la reconciliación: la memoria política de Antonio Machado durante el franquismo y la transición. Hispania, 234, 137-162. Disponible en: https://doi.org/10.3989/hispania.2010. v70.i234.160.

Rebollo Sánchez, F. (2008). Antonio Machado. Entre la literatura y el periodismo. Madrid: Fragua.

Ridruejo, D. (1941). El poeta rescatado. En Obras Completas de Antonio Machado. Madrid: Espasa Calpe.

- (1973). Antonio Machado, veinte años después de su muerte. En Entre literatura y política. Madrid: Seminarios y Ediciones.

Rubio, F. (1994). La herencia de la poesía de Antonio Machado en la postguerra. En P. Aubert (ed.). Antonio Machado hoy (pp. 419-428). Madrid: Casa de Velázquez.

Salaün, S. (2006). Antonio Machado o el nacimiento de un mito, 1900-1939. En J. Domenech (coord.). Hoy es siempre todavía. Curso internacional sobre Antonio Machado (pp. 668-693). Sevilla: Renacimiento-Ayuntamiento de Córdoba.

Sanmartín, R. (2010). La labor dramática de Manuel y Antonio Machado. Granada: Mágina. Santonja, G. (1994). Antonio Machado y su 'recuperación' durante los primeros tiempos del franquismo. En P. Aubert (ed.). Antonio Machado hoy (pp. 429-440). Madrid: Casa de Velázquez.

Serrano, C. (1990). Una dialéctica inconclusa: Antonio Machado y la crisis del liberalismo español. En Antonio Machado hoy. Actas del Congreso Internacional Conmemorativo del Cincuentenario de la Muerte de Antonio Machado (pp. 71-84). Sevilla: Alfar.

Sesé, B. (1980). Antonio Machado (1875-1939). Elhombre. ElPoeta. Elsoñador. Madrid: Gredos.

Torre, G. de y Albornoz, A. de (1964). Ensayo preliminar. En A. Machado. Obras: poesía y prosa. Buenos Aires: Losada.

Tuñón de Lara, M. (1997). Antonio Machado poeta del pueblo. Madrid: Taurus. 